\title{
ANALYSIS OF Paracoccidioides brasiliensis EXOANTIGENS STABILITY
}

Thesis: D. F. da SILVA submitted this dissertation for his Masters in Science at the Center for Disease Control, São Paulo State Secretariat of Health, CCD-SES-SP, São Paulo, São Paulo State, Brazil, 2005.

Advisor: Professor Adriana Pardini Vicentini

Co-advisor: Professor Cezar Mendes de Assis

ABSTRACT: Diagnosis by isolation of the microorganism from cultures provides the strongest evidence of infection by Paracoccidioides brasiliensis $(P b)$. However, isolation is not always possible and serological tests such as double immunodiffusion (ID) must be often employed. We analyzed the reaction profile of 75 serum samples from paracoccidioidomycosis (PCM) patients, by using ID, against nine different antigenic preparations of $\mathrm{Pb}$ : somatic antigen (SoAg), produced from $P b 113$ and Pb339 strains; cell-free antigen (CFAg), produced from Pb113 strain - both preparations were cultured in Fava-Netto's agar medium for 7 days at $36^{\circ} \mathrm{C}$; metabolic antigen (MAg), produced from Pb113 and Pb339 strains cultured in liquid NGTA (neopeptone, glucose, thiamine and asparagine) medium for 20 days at $36^{\circ} \mathrm{C}$; soluble components of the cell wall outer surface (SCCWOS), produced from $\mathrm{Pb} 113$ strain cultured in Fava-Neto's agar medium at $36^{\circ} \mathrm{C}$ for $5,10,15$, and 20 days; and Pb113 Negroni and Pb113 NGTA antigens, cultured for 20 days at $36^{\circ} \mathrm{C}$. Serum samples reactivity was $90 \%$ to AgSo and SCCWOS cultured for 5, 10, 15 and 20 days; $86.6 \%$ to CFAg; $83.3 \%$ to MAg; $80 \%$ to Pb113 NGTA antigen; and $76.6 \%$ to $\mathrm{Pb} 113$ Negroni antigen. Electrophoresis in 10\%SDS-PAGE showed high complexity of the protein fractions of SCCWOS, Pb113 Negroni and Pb113 NGTA antigens, which presented molecular weight between 25 and $170 \mathrm{kDa}$. Specificity and sensitivity of SCCWOS against serum pool from patients with chronic and acute forms of the disease were confirmed by immunoblot, which demonstrated that 25,43 , 60, 70, 85 and 160-kDa antigenic fractions of SCCWOS cultured for 5 and 10 days showed intense reactivity. We could demonstrate that SCCWOS of $P b$ are stable and show highly preserved antigenic fractions, which was proved by their high reactivity pattern to sera from different forms of PCM, anti- $P b$ antigen and anti-gp43 antisera.

KEY WORDS: Paracoccidioides, serological assay, paracoccidioidomycosis diagnosis, antigen-antibody reaction.

\section{CORRESPONDENCE TO:}

DÉCIO FRAGATA DA SILVA, Avenida Dr. Arnaldo, $11^{\circ}$ andar, sala 1109, São Paulo, 01246-902, SP, Brasil. Phone: +55 113068 2899. Fax: +55 1130682898.

Email: dfragata@yahoo.com.br. 